\title{
PHYTOREMEDIATION OF PETROLEUM HYDROCARBONS CONTAMINATED SOILS WITH ALFALFA (MEDICAGO SATIVA)
}

\author{
Charlotte Marchand ${ }^{1}$, Fabio Kaczala ${ }^{2}$, Yahya Jani $^{2}$, William Hogland ${ }^{2}$ \\ ${ }^{1}$ Biodiversity Centre of Montreal university 4101 Sherbrooke East Montreal, \\ Quebec H1X 2B2 Canada; charlotte.marchand@umontreal.ca \\ ${ }^{2}$ Biology and environmental sciences, Linnaeus University, 39182, Kalmar, \\ Sweden
}

\begin{abstract}
Underground storage tanks uses for waste cars draining contain many hazardous materials including hydrocarbons. These compounds pose a significant threat to the environment and affect negatively the health of living. Phytoremediation is an environmental friendly method used during the last few decades to eliminating organics pollutants from soil, sediment and water. The remediation capability of alfalfa (Medicago sativa) to treat petroleum-contaminated soil from an old car scrap yard in Nybro, Sweden was further investigated using greenhouse pot-scale experiments. After five months, alfalfa survival capacity and dry biomass were significantly lower in contaminated soil (CS) in comparison to non-contaminated soil (NCS). Only 5\% of plants survived in CS and petroleum hydrocarbon C10-C50 content in planted treatment were not statistically lower in comparison to the unplanted treatment. Further studies are in process to evaluate the possible degradation of hydrocarbons using organic amendment
\end{abstract}

\section{KEYWORDS}

PAHs, phytoremediation, compost, contaminated soil, Medicago sativa.

\section{INTRODUCTION}

Car scrap yards are an important source of end-of-life recycling for motor vehicles. However, these yards can be also a source of pollution by petroleum hydrocarbons from motor oil and brake pads. Impact of petroleum hydrocarbons on soil have been attracting considerable attention due to their persistence as well as their adverse effects(Kidd, Dominguez-Rodriguez et al. 2007). They have adverse effect for human health and also harmful effect for plants growth such as inhibition of seed germination and shortening of roots and shoots (Eom, Rast et al. 2007) 
Many remediation techniques have been use to clean up contaminated soil including mainly physical, chemical and biological methods (Mulligan, Yong et al. 2001). However, Physicochemical remediation methods are costly and not friendly for environment. An alternative method is the phytoremediation technique. It is define as the use of plants and their associated microorganisms, soil amendments and agronomic techniques to clean up environmental contaminants. (Wang, Chen et al. 2012).

$M$. sativa is one of the most used plant for the phytoremediation of organic pollutants (Fan, Li et al. 2008). This plant have a highly roots system suitable for phytoremediation of petroleum contaminated soil(Wei and Pan 2010). Alfalfa is a Fabaceae widely cultivated for it capacity to producing high-yield and high-quality forage(D'orazio, Ghanem et al. 2013). Leguminous are a good choice for phytoremediation because it have the capacity of fixing atmospheric nitrogen(Hutchinson, Banks et al. 2001). Generally, hydrocarbon contaminated soils are poor in nutrient specially nitrogen. Leguminous increase the amount of nitrogen in soil that may stimulate plant and microbial involve in hydrocarbon's remediation(D'orazio, Ghanem et al. 2013).

The aim of the present study was to investigate the phytoremediation of hydrocarbons contaminated soil from a leaking petrol tank by using L. Sadivum. In addition, tolerance of alfalfa in contaminated soil was evaluated.

\section{MATERIAL AND METHODS}

\subsection{Soil sample preparation}

The studied area was an old car scrap yard "Nybro Bildemontering" located in the city of Nybro, Southeastern part of Sweden $\left(56^{\circ} 45^{\prime} 0^{\prime \prime} \mathrm{N} ; 15^{\circ} 54^{\prime} 0^{\prime}\right.$ " E). This garage has been used to repair and drain cars since 1884. In this yard, there was a buried tank that received the waste oil from cars draining. During the emptying of this tank a great amount of oil was spilled and the soil got contaminated.. Sampling was done for both contaminated soils (CS) and non-contaminated soils (NCS) used as controls. Soils were collected at sampling depths of $1 \mathrm{~m}$. As soon as sampling was done, samples were homogenized, sieved through a $8 \mathrm{~mm}$ mesh and kept at $4 \pm 1{ }^{\circ} \mathrm{C}$ for the analysis.

\subsection{Soil characterization}

NCS and CS were analyzed for F1-F4 hydrocarbons (sum of all aromatic and aliphatic hydrocarbon compounds with chain lengths of C10-C50) by AGAT laboratory (Montreal. Quebec, Canada) according to the standard protocol provided by Canadian Council of Ministers of the Environment (http://www.ceaeq.gouv.qc.ca/methodes/pdf/MA400HAP11.pdf).

The extraction of the water phase from the fresh soils and compost was obtained through mechanical shake with agitation speed of $100 \mathrm{rpm}$ for $1 \mathrm{~h}$ at a solid-to-liquid ration (S:L) of 1:5 (w:v) with deionized water (Cheng, Lai et al. 2008). The suspensions were centrifuged twice at $16.000 \mathrm{x}$ g for 15 minutes at $13^{\circ} \mathrm{C}$. Dissolved oxygen (DO), $\mathrm{pH}$ and conductivity of the extracts were analysed with a HQ11d portable meter (Hach Company, USA). Total organic carbon (TOC), total nitrogen $\left(\mathrm{N}_{\mathrm{t}}\right)$, total phosphorus $\left(\mathrm{P}_{\mathrm{t}}\right)$ and chemical oxygen demand (COD were 
analyzed with Dr Lange cuvette tests (Dr Bruno Lange, GmbH\& CO. KG, Dusseldorf, Germany). Cuvettes were measured spectrophotometrically with a HACH XION 500 spectrophotometer. Lange methods are validated according to ISO 8466-1 (1990), DIN 32645 (1996) and DIN 38402 A51 (1986). Dry matter (DM) was determined after dried the soil samples at $105 \pm 5{ }^{\circ} \mathrm{C}$ until mass constancy is reached (ISO 11465 1993). Total organic matter (TOM) was determined as sample weight loss (previously oven-dried at $105^{\circ} \mathrm{C}$ ) upon ashing at $550^{\circ} \mathrm{C}$ for 16h in a muffle furnace (ASTM D 2974)(Cheng, Lai et al. 2008). Table 1 summarizes some physico-chemical characteristics, organics and inorganic contaminants of soils and compost.

Table 1: Physicochemical properties and petroleum hydrocarbons content in non-contaminated soils (NCS) and contaminated soils (CS)

\begin{tabular}{lccc}
\hline & Units & NCS & CS \\
\hline Texture & & Sandy Loam & Silt Loam \\
$\mathrm{pH}(1: 5, w / \mathrm{v})$ & & $7.07 \pm 0.42$ & $6.59 \pm 0.34$ \\
Dry matter & $\%$ & $91.78 \pm 0.16$ & $39.13 \pm 0.43$ \\
Organic matter & $\%$ & $9.5 \pm 0.59$ & $31.49 \pm 2.07$ \\
Dissolved oxygen & $\mathrm{mg} / \mathrm{L}$ & $6.67 \pm 0.12$ & $4.83 \pm 0.25$ \\
Conductivity & $\mathrm{us} / \mathrm{cm}$ & $65.93 \pm 2.47$ & $133.1 \pm 14.64$ \\
Chemical oxygen demand & $\mathrm{mg} / \mathrm{L}$ & $234.33 \pm 39.31$ & $86100 \pm 556.78$ \\
Total organic carbon & $\mathrm{mg} / \mathrm{L}$ & $33.2 \pm 4.95$ & $1221 \pm 8.72$ \\
Total nitrogen & $\mathrm{mg} / \mathrm{L}$ & $2.31 \pm 0.45$ & $3.03 \pm 0.03$ \\
Total phosphorus & $\mathrm{mg} / \mathrm{L}$ & $2.24 \pm 0.97$ & $1.59 \pm 0.46$ \\
Petroleum hydrocarbon C10-C50 & $\mathrm{mg} / \mathrm{kg}$ & $\mathrm{Nd}$ & $25250 \pm 3464.82$ \\
\hline
\end{tabular}

All weights and percentages are in terms of dry matter (DM). Values are averages with standard deviation $(\mathrm{n}=3)$.

Nd: not detected

\subsection{Greenhouse pot-culture experiment}

The soil samples (5kg) were placed in 12L plastic pots (25 cm diameter x $25 \mathrm{~cm}$ height). Seeds of $M$. sativa with an optimal germinability of $80 \%$ were used. Seeds were sterilized in $10 \%(\mathrm{v} / \mathrm{v})$ hydrogen peroxide for $10 \mathrm{~min}$, washed with distilled water 7 times with manual shake very gently(Wei and Pan 2010). Seed were germinated in petri plates with distilled water. Seed were placed in a dark cabinet at room temperature for 4 days. Twenty seedlings of uniform size were selected and then trans-planted to each designated plots. Pots watered when required with deionized water to maintain the soil moisture during plant growth. Growth was allowed for 5 months under greenhouse-controlled conditions: 16:8 Light/Dark, temperature of $25 \pm 2{ }^{\circ} \mathrm{C}$, photosynthesis active radiation of $270 \mathrm{umol} \mathrm{m}^{-2} \mathrm{~s}^{-1}$ and $65 \pm 5 \%$ relative air humidity.

At the end of the experiment, shoot were cut just above the soil surface and washed with deionized water. Each pot was then emptied and roots were separated from the soil by washing with tap water. Dry biomass weight (DW) was assessed after oven drying for $48 \mathrm{~h}$ at $80^{\circ} \mathrm{C}(\mathrm{Novo}$, Covelo et al. 2013).

\section{Results and discussions}




\subsection{Characteristics of soils}

The investigated soils - non-contaminated (NCS) and contaminated soil (CS) - were characterized in terms of physico-chemical parameters and petroleum hydrocarbon C10-C50 contents (Table 1). The results showed that the $\mathrm{pH}$ of soils and compost was slightly acidic. Reasonably, the results have shown much higher contents of COD and TOC in CS in comparison to NCS (Table 1). Whereas COD values as high as $86100 \pm 556.78 \mathrm{mg} / \mathrm{L}$ were detected in CS, NCS had COD of $234.33 \pm 39.31 \mathrm{mg} / \mathrm{L}$. Furthermore, TOC values ranged between $1221 \pm 8.72$ and $33.2 \pm 4.95$ for CS and NCS respectively confirming the higher amount of carbon contents in the contaminated media. Another parameter that was reasonably found in higher contents in CS in comparison to NCS was the total organic matter \% (TOM) with $31.49 \pm 2.07 \%$ and $9.5 \pm 0.59$ $\%$ for CS and NCS respectively.

\section{Analysis of plants growth}

At the end of five months growth period, survival capacity of alfalfa were only $5 \%$ in contaminated soil but $82 \%$ in non-contaminated soil, as shown in (Fig.1). Results also showed that alfalfa shoots and roots biomass were significantly similar lower in CS in comparison to NCS (Fig.1). Alfalfa was strongly affected by the hydrocarbons and it showed a low tolerance to theses contaminants. Roots were highly affected compared to the effects of the shoots. This result was previously observed by(D'orazio, Ghanem et al. 2013) who investigated the potential to used alfalfa and two others plants for phytoremediation.
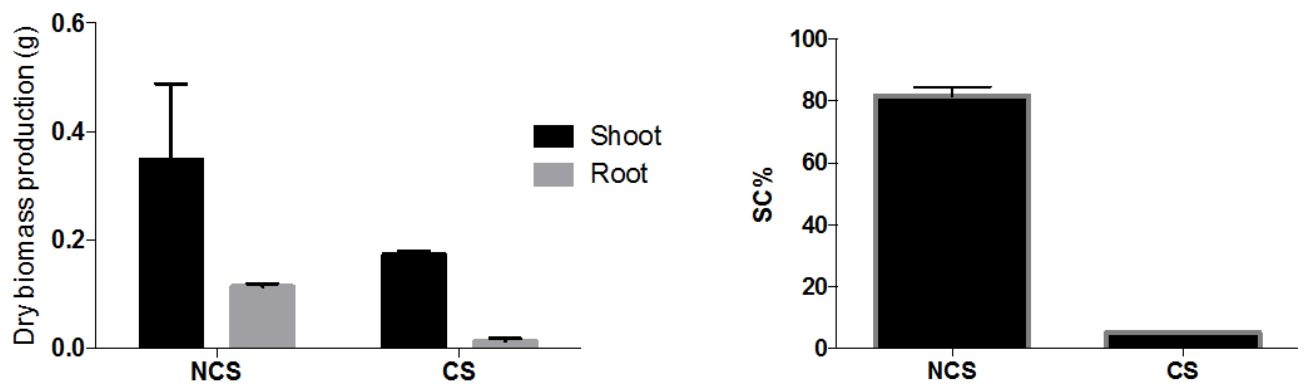

Figure 1: Survival capacity (SC) and dry biomass production of $M$. sativa after five months.

\subsection{Petroleum hydrocarbons degradation}

During the growth of $M$. sativa, petroleum hydrocarbon C10-C50 content in CS was not statistically significant in planted soil in comparison to unplanted (Fig. 2). Similar results were found in previous study: (Chigbo and Batty 2013) compared phytoremediation potential using freshly spiked soil or aged soil. These results did not show any evidence of phytoremediation in aged soil. This could be du to the fact that in aged contaminated soil, pollutants are less bioavailable due o their sequestration and stored in the organic matter. Consequently, pollutant are less assessable to microbes degradation or diffusion(Alexander 2000). Many researchers reported the use of phytoremediation with spiking petroleum hydrocarbon or metals and compare 
their degradation rate in planted and unplanted. Some of the results showed a successful phytoremediation affects. However, phytoremediation with aged soil is lower compare to freshly contaminated soil(Chigbo and Batty 2013).

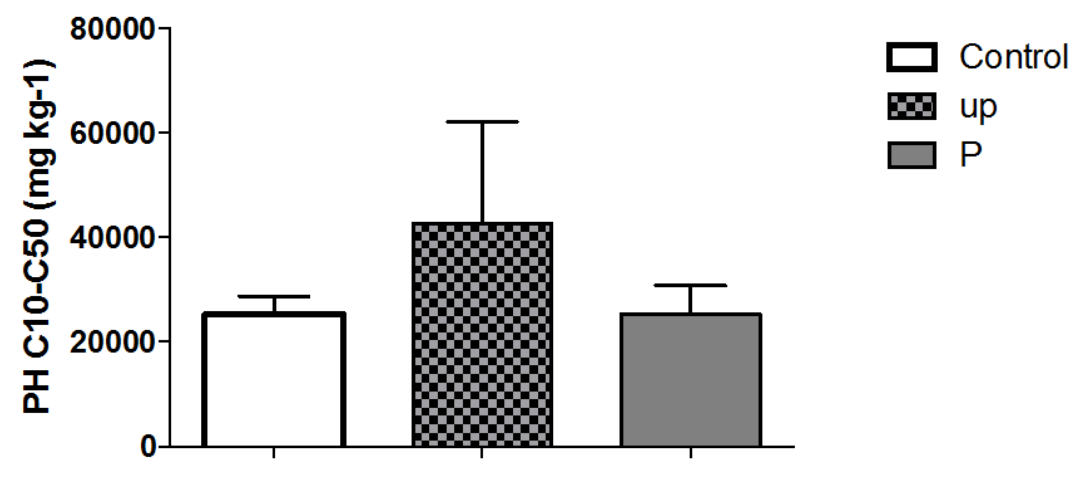

Figure 2: Petroleum hydrocarbons C10-C50 content (mg/kg dry matter) in contaminated soil (CS) after five months phytoremediation with alfalfa (P: planted). Control is the content of PH C10-C50 before phytoremediation and $\mathrm{Up}$ is the content after phytoremediation in unplanted treatment. Mean for each treatment are the means of two replicates and error bars represent the standard deviations.

\section{CONCLUSION}

It was clear that the potential to use phytoremediation with alfalfa was not significant to contaminated soil with hydrocarbons. Dry biomass production and survival capacity of alfalfa were highly reduced in CS compared to NCS. Three hypotheses may be suggested: (1) Hydrocarbons were strongly bound to the solid-phase after almost thirty-year aging process or (2) the limited duration of phytoremediation (5 months) was not enough and (3) the chosen plants were inappropriate for an effective removal of these compounds under the experimental conditions described in this study. Further studies are in process to improve the efficiency of this phytoremediation using organic amendment.

\section{REFERENCES}

Alexander, M. (2000). "Aging, bioavailability, and overestimation of risk from environmental pollutants." Environmental Science \& Technology 34(20): 4259-4265.

Benabderrahim, M. A., M. Haddad, H. Hamza and A. Ferchichi (2011). "Germination and emergence variability of alfalfa (Medicago sativa L.) landraces collected in Southern Tunisia oases." Spanish Journal of Agricultural Research 9(1): 135-143.

Cheng, K. Y., K. M. Lai and J. W. C. Wong (2008). "Effects of pig manure compost and nonionic-surfactant Tween 80 on phenanthrene and pyrene removal from soil vegetated with Agropyron elongatum." Chemosphere 73(5): 791-797. 
Chigbo, C. and L. Batty (2013). "Phytoremediation potential of Brassica juncea in Cu-pyrene cocontaminated soil: Comparing freshly spiked soil with aged soil." Journal of Environmental Management 129: 18-24.

D'orazio, V., A. Ghanem and N. Senesi (2013). "Phytoremediation of Pyrene Contaminated Soils by Different Plant Species." Clean-Soil Air Water 41(4): 377-382.

Eom, I. C., C. Rast, A. M. Veber and P. Vasseur (2007). "Ecotoxicity of a polycyclic aromatic hydrocarbon (PAH)-contaminated soil." Ecotoxicology and Environmental Safety 67(2): 190205.

Fan, S., P. Li, Z. Gong, W. Ren and N. He (2008). "Promotion of pyrene degradation in rhizosphere of alfalfa (Medicago sativa L.)." Chemosphere 71(8): 1593-1598.

Hutchinson, S. L., M. K. Banks and A. P. Schwab (2001). "Phytoremediation of aged petroleum sludge: effect of inorganic fertilizer." J Environ Qual 30(2): 395-403.

Kidd, P. S., M. J. Dominguez-Rodriguez, J. Diez and C. Monterroso (2007). "Bioavailability and plant accumulation of heavy metals and phosphorus in agricultural soils amended by long-term application of sewage sludge." Chemosphere 66(8): 1458-1467.

Mulligan, C., R. Yong and B. Gibbs (2001). "Remediation technologies for metal-contaminated soils and groundwater: an evaluation." Engineering geology 60(1): 193-207.

Novo, L. A. B., E. F. Covelo and L. Gonzalez (2013). "Phytoremediation of amended copper mine tailings with Brassica juncea." International Journal of Mining Reclamation and Environment 27(3): 215-226.

Wang, M. C., Y. T. Chen, S. H. Chen, S. W. C. Chien and S. V. Sunkara (2012).

"Phytoremediation of pyrene contaminated soils amended with compost and planted with ryegrass and alfalfa." Chemosphere 87(3): 217-225.

Wei, S. Q. and S. W. Pan (2010). "Phytoremediation for soils contaminated by phenanthrene and pyrene with multiple plant species." Journal of Soils and Sediments 10(5): 886-894. 